Danielle Allard

School of Library and Information Studies, University of Alberta, Alberta, Canada

Amy Lebovitch

Sex Professionals of Canada (SPOC), Toronto, Ontario, Canada

Jenn Clamen

Stella, l'amie de Maimie, Montréal, Québec, Canada

Shawna Ferris

Women's and Gender Studies, University of Manitoba, Winnipeg, Manitoba, Canada

Micheline Hughes

Indigenous Studies, University of Manitoba, Winnipeg, Manitoba, Canada

\title{
Ethical accountability and high-stakes recordkeeping: Discussions from the Sex Work Activist Histories Project (Panel)
}

\begin{abstract}
Résumé:
Including both academic and sex work activist community partners, panel members will discuss established and developing practices and key findings from the Sex Work Activist Histories Projects' first two years as we collected and archived sex work activist histories. We draw from feminist and Indigenous frameworks of ethical, affective, and relational accountability (among groups, between academics and non-academics involved in the project, and between people and their records/histories) to productively consider how project relationships might be cultivated that are mutually accountable to the varied and complex analytical and affective positionalities of project members as they work together.
\end{abstract}

\section{Introduction}

A vibrant, influential, and connected Canadian sex work rights movement has, for decades now, been engaging in an array of remarkable resistance projects that counter dangerous sex work laws and dehumanizing public perceptions about sex workers. The Sex Work Activist Histories Project (SWAHP) is an interdisciplinary research initiative to record and disseminate the radical knowledges, activist expertise, and alternative histories created by many of these activists. SWAHP has set out to (1) collect or record, write, curate, preserve, and/or engage with more than forty years of activist histories from some of the longest-standing sex worker-led organizations in Canada; (2) augment, develop, and implement methodologies and best practices for valuing and sharing knowledge and expertise between non-academic and academic communities; (3) develop methodologies and best practices for the sharing/recording and 
preservation of alternative histories told/represented in ways that matter to their creators, including the Sex Work Database - a community archives being created by the project, and (4) support and contribute to feminist anti-violence scholarship and activism that contests conceptions of violence against certain people as deserved and expected. An ongoing challenge in doing this work collaboratively are the divergent vocabularies, project priorities, accountabilities, understandings of what is at stake, and risks and vulnerabilities between and among the sex work activist organization members and academic partners in this relationship/partnership. At the same time, we share the work of project administration and decision making, record arrangement and description, and the use of analytical and critical thinking skills to further project goals. Perhaps most importantly, we share a wish to explore and uncover how we might put archival processes at the service of sex work activism.

This panel will discuss established and developing practices and key findings from SWAHP's first two years as we worked with our partners to collect and archive their histories. We will first introduce feminist and Indigenous notions of ethical, affective, and relational accountability (among groups, between academics and non-academics involved in the project, and between humans and their records/histories) to explore our work together (Agustin, 2004; Brown \& Strega, 2005; Caswell \& Cifor, 2016; UNAIDS \& WHO, 2007; Wilson, 2012). Caswell and Cifor, for example, draw from feminist ethics of care to suggest that "archivists [should be] seen as caregivers, bound to records creators, subjects, users, and communities through a web of mutual affective responsibility" (2016, p. 23). We elaborate this notion to consider how all participants in SWAHP have differently situated responsibilities, obligations, stakes in the project, and experience different vulnerabilities through their participation on the project. Our discussions will consider both the divergences or differences between academic and non-academic project partners, our convergence or common ground, AND the bridges we must build between academic and non-academic concerns and practices to establish and develop methodologies and practices that inform SWAHP's ongoing collaborations including the development of sex-work activist histories, archives, and related sex work activism. Drawing on feminist and Indigenous notions of ethical and relational accountability provides a framework for us to productively consider how to be mutually accountable to our varied and complex analytical and affective positionalities in the specific context of this work and as we move forward together.

\section{Panel format}

Rather than identifying the specific arguments that each member of the panel will make, below, we identify instead broad perspectives and positionalities brought to our partnership by differently located members to demonstrate our divergent and convergent responsibilities, obligations, expertise, and the stakes with which we are contending. Each member of the panel will introduce themselves and their relationship to the project. Panelists will then be invited to respond individually to a series of related questions, as well as to each other. Finally, we will invite the audience to offer their own thoughts and experiences to this conversation about working in complex or community partnerships.

\section{Participants}




\section{Sex Work Activist Organization Contributors: Sex Professionals of Canada (SPOC) representative Amy Lebovitch Stella, l'amie de Maimie representative Jenn Clamen}

The non-academic, sex work activist group representatives in this panel discussion will consider and discuss both their group and individual responsibilities and accountabilities to the project as well as the 'high stakes' nature of this work. The context is high stakes for some groups because of the possibility that SWAHP might be the only place or time that their histories are recorded and/or formally recognized since community groups may not have the pre-existing funding or infrastructure to do this work alone. These representatives sometimes feel pressure to acquiesce to academic timelines, frameworks, and expectations that do not align with their own goals in order to ensure that the work gets done. The context is also high stakes for many individuals because of considerations around personal legacies; because many activists' personal lives and experiences - some of which are secret, or private, or violent, or intertwined with others' lives and experiences they do not have permission to tell or record-are connected with group records and histories.

These contributors will also emphasize that activist histories from marginalized groups are often difficult histories because of the losses to groups and individuals that they include. On the other hand, contributors often feel a strong sense of pride at seeing the depth of history and significant labour, recordkeeping and otherwise, that has gone into organizing for their own rights. Re-telling and recording histories can therefore be associated with joy, pride, or exhilaration as well as trauma, mourning, anger, and frustration. Group representatives will elaborate how SWAHP work requires a range of expertise and labour, including significant emotional labour, on the part of activists. Within academic and LIS and archival practice circles at least, this emotional labour is rarely accounted for when academics describe their work, how they do it, and why it matters.

\section{Academic Contributors: Women's and Gender Studies associate professor Shawna Ferris; Library and Information Studies/Archival Studies assistant professor Danielle Allard; Indigenous Studies doctoral candidate Micheline Hughes}

The academic contributors on this panel discussion will each consider and discuss their academic and ethical responsibilities within each of the disciplines from which they come. For some of the reasons identified by the non-academic contributors, the context is also 'high stakes' politically, emotionally, academically, and historically for SWAHP academics. These contributors will focus on the ethics of doing ostensibly academic labour and archival practice with and for groups to whom they are outsiders, but with whom they consistently work to maintain good relationships. The academics will also examine the emotional labour of SWAHP recordkeeping-labour for which academic training does not prepare researchers or LIS practitioners. Recognizing that because the histories being framed and recorded are not theirs, the academic team members may not experience the more difficult emotions associated with SWAHP. They have learned that they must nonetheless prepare themselves emotionally for the responsibilities of witnessing/receiving complicated histories. Contrary to traditional education about LIS and archival practice, contributors argue that they have also learned to anticipate and make room for their own and others' affective responses to SWAHP activities. 
Academic contributors will also explore how this work requires them to open up their definitions of what is a record, what is an archives, and what is a best practice, as they discuss and prioritize the understanding of these concepts with non-academic stakeholders. As with other community archives, because this project focuses on preserving histories in ways that matter to their creators, foundational and traditional archival concepts are revisited if/when they don't serve the goals of the project (Zavala, Migoni, Caswell, Geraci \& Cifor, 2017). Opening up and questioning these definitions and practices can feel risky. We must also acknowledge however that the risks are not equivalent to the risks that non-academic contributors face as they work to preserve and tell their own histories.

To be very clear, the sex work activist community members participating at this conference have a long history of participating in academic settings and working alongside academics to improve the research, journalism, cultural heritage, and social narratives that are created about them and without them. We offer this conversation at this conference because we believe it has significant value for LIS researchers and educators engaging in, speaking to, and teaching about community-based research and practice. We wish to generate honest discussion that can make visible the high stakes of this work as well as the bridges that must be built in order to work together on the SWAHP project and to be accountable to each other and our various affiliations. More broadly, this work aligns with our shared commitments to re-imagine LIS research and institutional contexts that are supportive of rather than harmful to sex workers and sex work activism.

\section{Reference List:}

Agustin, L. (2004). Alternate ethics, or: Telling lies to Researchers. Research for Sex Work, 7, 67.

Brown, L., Strega, S. (2005). Research as Resistance: Critical, Indigenous, \& Anti-oppressive Approaches. Toronto: Canadian Scholars' Press.

Caswell, M. \& Cifor, M. (2016). From human rights to feminist ethics: Radical empathy in the archives. Archivaria, 81, 23-83.

UNAIDS and WHO. (2007). Ethical considerations in biomedical HIV prevention trials. Geneva: UNAIDS.

Wilson, S. (2012). Research is ceremony: Indigenous research methods. Black Point, NS: Fernwood Publishing Co. Ltd.

Zavala, Z., Migoni, A.A., Caswell, M., Geraci, N. \& Cifor, M. (2017) 'A process where we're all at the table': community archives challenging dominant modes of archival practice, Archives and Manuscripts, 45(3), 202-215. 